\title{
The value of long noncoding RNA PANDAR as a biomarker of prognosis in carcinomas: a meta-analysis
}

\author{
Xin Yan ${ }^{1}$, Yanting Zhu ${ }^{1}$, Fangwei Li ${ }^{1}$, Wenhua Shi ${ }^{1}$, Jian Wang ${ }^{1}$, Qingting Wang ${ }^{1}$, \\ Qianqian Zhang ${ }^{1}$, Limin Chai ${ }^{1}$ and Manxiang Li $^{1}$ \\ ${ }^{1}$ Department of Respiratory and Critical Care Medicine, The First Affiliated Hospital of Xi'an Jiaotong University, Xi'an, \\ Shaanxi 710061, China
}

Correspondence to: Manxiang Li, email: manxiangli@hotmail.com

Keywords: PANDAR; cancer; biomarker; prognosis; meta-analysis

Received: July 15, 2017 Accepted: December 04, $2017 \quad$ Published: January 02, 2018

Copyright: Yan et al. This is an open-access article distributed under the terms of the Creative Commons Attribution License 3.0 (CC BY 3.0), which permits unrestricted use, distribution, and reproduction in any medium, provided the original author and source are credited.

\section{ABSTRACT}

Promoter of CDKN1A antisense DNA damage activated RNA (PANDAR) has been demonstrated to be aberrantly expressed in various types of cancer and might be serve as a potential biomarker for human cancers. The present study conducted a meta-analysis to investigate whether the expression of IncRNA PANDAR was associated with prognosis and clinicopathological features in relevant cancers. 10 eligible studies with a total of 1211 patients were collected by searching the electronic bibliographic databases, the results show that high expression level of PANDAR could significantly predict shorter OS in cancer patients (HR $=\mathbf{2 . 0 8}, 95 \%$ CI: 1.55-2.80, $P$ $<0.001$ ) except in patients with non-small cell lung cancer (NSCLC). There was also a significant association between high level of PANDAR and advanced TNM stage (OR $=2.80,95 \% \mathrm{CI}=1.57-4.99, P<0.001)$, positive lymph node metastasis $(O R=2.92$, $95 \% \mathrm{CI}=1.92-4.45, P<0.001)$, larger tumor size $(\mathrm{OR}=1.41,95 \% \mathrm{CI}=1.04-1.89$, $P=0.03)$ and poor tumor differentiation $(O R=1.53,95 \% C I=1.09-2.15, P=0.01)$. In conclusion, the meta-analysis results indicate that increased expression level of PANDAR was associated with unfavorable prognosis and might serve as a predictive factor for advanced clinicopathological features in various cancers.

\section{INTRODUCTION}

Cancer is a major public health problem and the second leading cause of death in the United States, besides, it is estimated that $1,688,780$ new cancer cases and 600,920 cancer deaths are projected to occur in 2017 [1]. Furthermore, it is set to become a major cause of morbidity and mortality in the coming decades worldwide [2]. However, until now the mechanisms of oncogenesis have not been fully clarified due to its complex and elusive process. Tumor markers gradually sparked considerable attention for their striking role in identifying the tumor at an early stage when it is still localized or even before clinical symptoms appear [3]. Apart from diagnosis, biomarkers can offer physicians actionable information leading to optimal therapy and prognostication of disease progression [4]. Thus, it is urgent to seek out more markers to have a better control of cancer.

Long noncoding RNAs are non-coding RNAs more than $200 \mathrm{bp}$ in length with limited protein-coding capacity [5]. Mounting evidence indicate that lncRNAs play essential roles in diverse biological processes including tumorigenesis $[6,7]$. With regard to the role in cancer, lncRNAs can not only regulate the expression of distinct gene which transforms the phenotype of cancer cells in transcriptional processes, moreover, some of them might function as a mediator of ubiquitination of antimetastasis protein in post-transcriptional processes [8-11]. Meanwhile, key tumor suppressors or oncogenes such as p53 and Myc can in turn regulate lncRNAs transcriptionally $[9,12]$. Recently, it has been demonstrated that lncRNAs can act as competing endogenous RNA(ceRNA) by competitively binding to a miRNA response element(MRE) and protect target mRNAs from repression [13, 14]. Such model has been shown to be critical in tumorigenesis. Moreover, a novel lncRNA, lnc-EGFR has been recognized to be involved in immunosuppression in human HCC by promoting Treg cell differentiation through being a potential enhancer of EGFR and its downstream [15]. 
Indeed, the role of IncRNAs in cancer development has been revealed in numerous studies. For example, IncRNA, highly up-regulated in liver cancer(HULC) is found to regulate the interaction of YB-1 with certain oncogenic mRNAs including cyclin D1, cyclin E1, and matrix metalloproteinase 3 , consequently accelerates the translation of these mRNAs in the process of tumorigenesis [16]. Besides, IncRNA prognosis-associated gallbladder cancer (PAGBC) acts as an "sponge" to competitively binds to the tumor suppressive microRNAs miR-133b and miR511 to promote tumor growth and metastasis [17]. Hence, lncRNAs have been implicated as promising markers for cancer diagnosis, prognosis and therapeutics [18].

Promoter of CDKN1A antisense DNA damage activated RNA (PANDAR) is a newly identified lncRNA that is localized at chromosome 6 and has a length of 1506 nucleotides. It is induced during DNA damage in a p53-dependent manner and inhibits the expression of apoptotic genes [19]. Aberrant PANDAR expression is reported in a variety of human cancers, including bladder cancer, breast cancer, osteosarcoma etc [20-23]. It exerts numerous molecular functions, such as promoting cell proliferation, invasion, epithelial-mesenchymal transition and metastasis, besides, it can suppress tumor cell apoptosis [20-25]. Besides, plentiful studies have shown that PANDAR abnormal expression is associated with prognosis of human cancers [26-34]. However, most individual studies reported are so limited in discrete and controversial outcome as well as small sample size. To our knowledge, no systematic meta-analysis has been conducted to evaluate the relationship between IncRNA PANDAR and the relevant clinical outcomes of various carcinomas. According to this, we conducted a quantitative meta-analysis to elucidate the prognostic value of lncRNA PANDAR expression in patients with cancer by systematically summarizing all eligible articles.

\section{RESULTS}

\section{Eligible literatures}

A total of 288 articles were retrieved from several different databases. After excluding 176 duplicate publications, 112 papers were further reviewed of titles, abstracts and full-texts, finally 10 articles were selected in the current meta-analysis due to meeting the inclusion criteria mentioned in methods. The selection procedure with more details was presented by a flow diagram in Figure 1.

\section{Study characteristics}

The main characteristics of 10 eligible articles were summarized in Table 1. The studies were published between 2015 and 2017 and the sample size ranged from 31 to 482 . The whole patients were divided into high and low lncRNA PANDAR group on the basis of qRT-PCR measurement results. All of studies were conducted in China and there were 9 kinds of carcinomas among them, including nonsmall cell lung cancer, colorectal cancer, clear cell renal cell carcinoma, cholangio carcinoma, renal cell carcinoma, gastric cancer, hepatocellular carcinoma, pancreatic ductal adenocarcinoma and bladder cancer. Of note, the median and mean values were applied as the cut-off value in articles.

\section{The association between PANDAR expression and prognosis of human cancers.}

To elucidate the association between the PANDAR expression and overall survival of all cancers, a total of 1125 patients with HRs and 95\% CIs were included. The random effects model was first chosen due to the existence of obvious heterogeneity $\left(I^{2}=80 \%\right)$, and the HR of high PANDAR expression group versus the low PANDAR expression group was $1.64(95 \%$ CI: $0.89-2.89, P=0.086)$. After removing each study in turn from the pooled analysis, we discovered that only by excluding the study from Han et al. 2015, the heterogeneity could be significantly reduced to lower than $50 \%$, which made the result more stable and convincing. Hence, we excluded the mentioned study and a fixed effects model was then employed as the absence of obvious heterogeneity $\left(I^{2}=39.6 \%\right)$. As indicated in Figure 2, enforced PANDAR expression was predictive of unfavorable $\mathrm{OS}$ in various carcinomas $(\mathrm{HR}=2.08,95 \%$ CI: $1.55-2.80, P=0.000)$. The subgroup analysis in a fixed or random effects model was conducted by cancer types, sample sizes, study quality and follow-up months based on the potential heterogeneity (Figure 3). For studies evaluating OS in different types of cancer, the promoted PANDAR expression could estimate worse outcome in digestive system, but not in non-digestive system malignancies, with the pooled HR of $2.45(95 \%$ CI: $1.77-$ $3.39, P=0.000)$, and 0.99 (95\% CI: 0.49-1.99, $P=0.966$ ) respectively (Figure 3A). In addition, it revealed a significant association between increased PANDAR expression and OS in studies with high quality (Figure 3B), sufficient sample size ( $\geq 100$ ) (Figure 3C) and ample follow-up time ( $\geq 60$ months) (Figure 3D). No significant heterogeneity was detected across studies within the subgroups.

\section{Correlation between PANDAR expression and clinical characteristics in patients with cancer}

We collected all the clinicopathological information from the included studies to do a further meta-analysis for the association between PANDAR expression level and clinicopathological characteristics. As shown in Figure 4 , the increased PANDAR expression was significantly associated with advanced TNM stage ( $\mathrm{OR}=2.80,95 \% \mathrm{CI}$ $=1.57-4.99, P<0.001$, Figure 4A), positive lymph node metastasis $(\mathrm{OR}=2.92,95 \% \mathrm{CI}=1.92-4.45, P<0.001$, Figure 4B), larger tumor size $(\mathrm{OR}=1.41,95 \% \mathrm{CI}=1.04$ $1.89, P=0.03$, Figure $4 \mathrm{C}$ ), and poor tumor differentiation $(\mathrm{OR}=1.53,95 \% \mathrm{CI}=1.09-2.15, P=0.01$, Figure 4D). 
Table 1: Summary of included eligible studies for meta-analysis in the present study

\begin{tabular}{|c|c|c|c|c|c|c|c|c|c|c|c|}
\hline Author & Year & Region & $\begin{array}{c}\text { Tumor } \\
\text { type }\end{array}$ & $\begin{array}{r}\text { Clinical } \\
\text { stage }\end{array}$ & $\begin{array}{c}\text { Sample } \\
\text { size }\end{array}$ & $\begin{array}{c}\text { PANDAR } \\
\text { assay }\end{array}$ & $\begin{array}{r}\text { Cut-off } \\
\text { value }\end{array}$ & $\begin{array}{c}\text { Outcome } \\
\text { mesure }\end{array}$ & $\begin{array}{r}\text { Hazard } \\
\text { ratios }\end{array}$ & $\begin{array}{l}\text { Follow- } \\
\text { up } \\
\text { months }\end{array}$ & $\begin{array}{l}\text { Quality } \\
\text { (estimate } \\
\text { on the } \\
\text { REMARK } \\
\text { guideline) }\end{array}$ \\
\hline $\begin{array}{l}\text { Peng et } \\
\text { al.[31] }\end{array}$ & 2015 & China & $\mathrm{HC}$ & I/II, III/IV & 482 & qRT-PCR & mean & OS & $\mathrm{HR} / \mathrm{KM}$ & 60 & 65 \\
\hline $\begin{array}{l}\text { Han et } \\
\text { al.[26] }\end{array}$ & 2015 & China & NSCLC & I/II, III/IV & 140 & qRT-PCR & mean & OS & $\mathrm{HR} / \mathrm{KM}$ & 60 & 65 \\
\hline $\begin{array}{l}\text { Zhan et } \\
\text { al.[21] }\end{array}$ & 2016 & China & $\mathrm{BC}$ & I/II, III/IV & 55 & qRT-PCR & NA & NA & NA & NA & 30 \\
\hline $\begin{array}{l}\text { Ma et } \\
\text { al.[30] }\end{array}$ & 2016 & China & $\mathrm{GC}$ & I/II, III/IV & 100 & qRT-PCR & NA & OS & $\mathrm{HR} / \mathrm{KM}$ & 36 & 70 \\
\hline Jin et al.[27] & 2016 & China & $\mathrm{RCC}$ & I/II, III/IV & 48 & qRT-PCR & mean & OS & KM & 60 & 50 \\
\hline $\begin{array}{l}\text { Xu1 et } \\
\text { al.[32] }\end{array}$ & 2017 & China & $\mathrm{CC}$ & I/II, III/IV & 67 & qRT-PCR & NA & OS & $\mathrm{HR} / \mathrm{KM}$ & 60 & 75 \\
\hline $\begin{array}{l}\mathrm{Xu} 2 \text { et } \\
\text { al.[33] }\end{array}$ & 2017 & China & CCRCC & I/II, III/IV & 62 & qRT-PCR & median & OS & $\mathrm{HR} / \mathrm{KM}$ & 50 & 65 \\
\hline Lu et al.[29] & 2017 & China & $\mathrm{CRC}$ & I/II, III/IV & 124 & qRT-PCR & median & OS & $\mathrm{HR} / \mathrm{KM}$ & 60 & 85 \\
\hline Li et al.[28] & 2017 & China & $\mathrm{CRC}$ & I/II, III/IV & 102 & qRT-PCR & median & OS & $\mathrm{HR} / \mathrm{KM}$ & 60 & 75 \\
\hline $\begin{array}{l}\text { Jiang et } \\
\text { al.[34] }\end{array}$ & 2017 & China & PDAC & NA & 31 & qRT-PCR & NA & NA & NA & NA & 40 \\
\hline
\end{tabular}

HR, hazard ratio; OS, overall survival; KM, Kaplan-Meier; qRT-PCR, quantitative real-time PCR; HC, hepatocellular carcinoma; GC, gastric cancer; RCC, renal cell carcinoma; CC, cholangio carcinoma; CCRCC, clear cell renal cell carcinoma; CRC, colorectal cancer; NSCLC, non-small cell lung cancer; BC, bladder cancer; PDAC, pancreatic ductal adenocarcinoma

\section{Publication bias}

The potential publication bias was assessed by funnel plot and Begg's bias test. The funnel plot was showed in Figure 5 and the $P$ value of the Begg's test was 1.000 for OS of enrolled studies, suggesting that there was no significant publication bias in meta-analysis.

\section{Sensitivity analysis}

The stability of conclusion was evaluated by sensitivity analysis. The result indicated that the conclusions were stable because the pooled HR was not significantly affected by the exclusion of any single study (Figure 6).

\section{DISCUSSION}

With the rapid development of high-throughput RNA sequencing and cancer genomics, numerous studies highlight the significance of IncRNAs in various human cancers for their imperative roles in many cancer-related processes including tumorigenesis, metastasis and angiogenesis [3538]. Being one of the promising novel biomarkers with prognostic value, LncRNA PANDAR is initially identified in human fetal lung fibroblasts and has been demonstrated to be involved in diverse cancer cell processes including proliferation, apoptosis, invasion and migration. For instance, Study from Xu et al find that PANDAR silencing can significantly induce cell cycle arrest in the G1 phase and promote cell apoptosis, besides, Akt phosphorylation and mTOR expression levels are down-regulated after transfection with si-PANDAR in clear cell renal cell carcinoma [33]. In breast cancer, PANDAR regulate the G1/S transition of breast cancer cells by suppressing p16(INK4A) expression, which results in the cell growth and colony formation [20]. In cholangiocarcinoma, PANDAR depletion inhibits the cell proliferation by restraining the expression of Bcl-2 and increasing the expression of BAX. Besides, cell invasion and migration are impeded along with the striking decrease of N-cadherin and Vimentin followed by si-PANDAR treatment [32]. In the aspect of prognostic role of PANDAR, several studies elucidate that PANDAR aberrant expression is prone to be involved in prognosis in various types of cancer, including hepatocellular carcinoma, gastric cancer, colorectal cancer, non-small cell lung cancer, renal cell carcinoma and cholangiocarcinoma. All in all, the collective evidence implies the oncogenesis role of PANDAR in various carcinomas. 


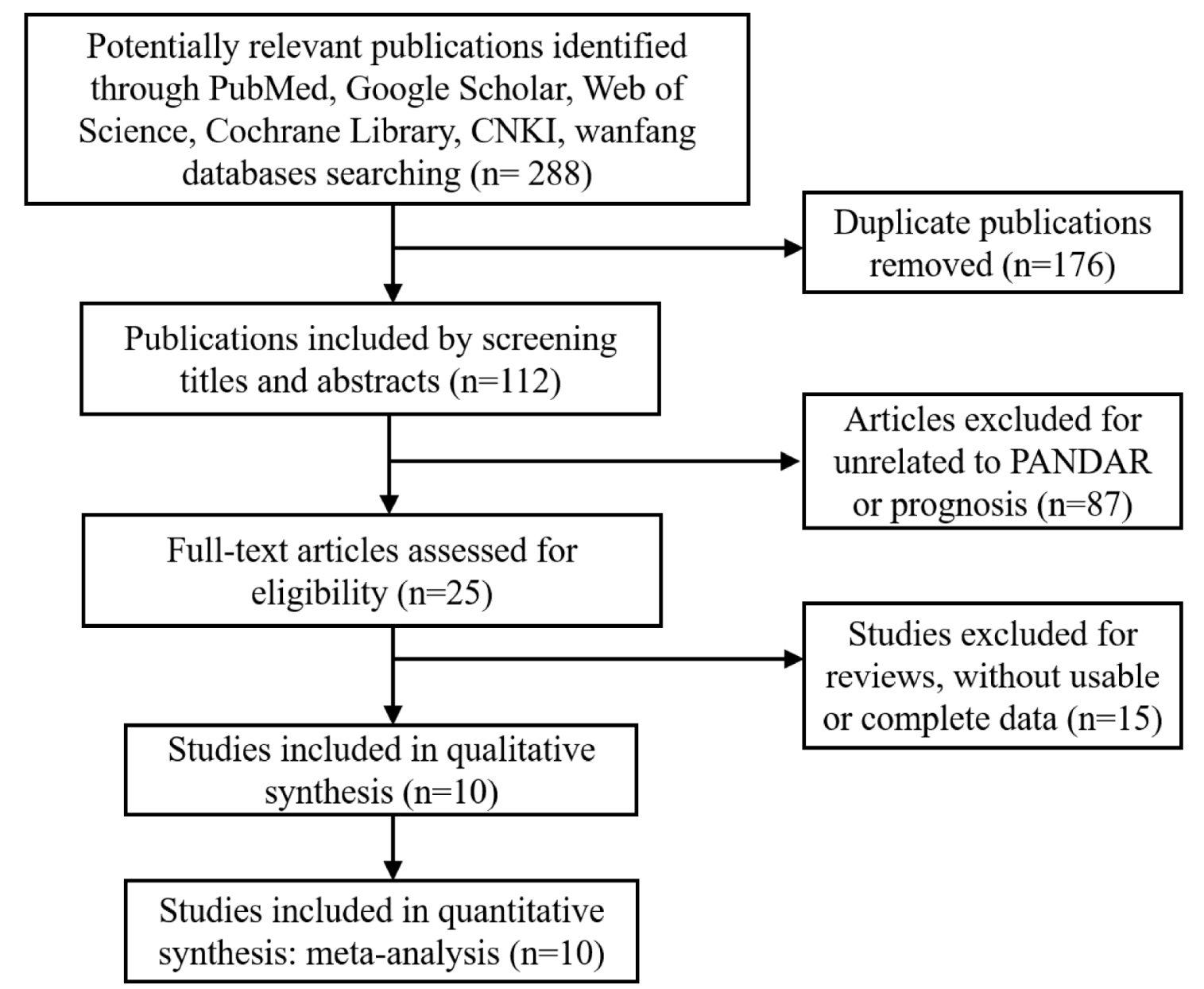

Figure 1: The flow diagram of study search and selection for meta-analysis.

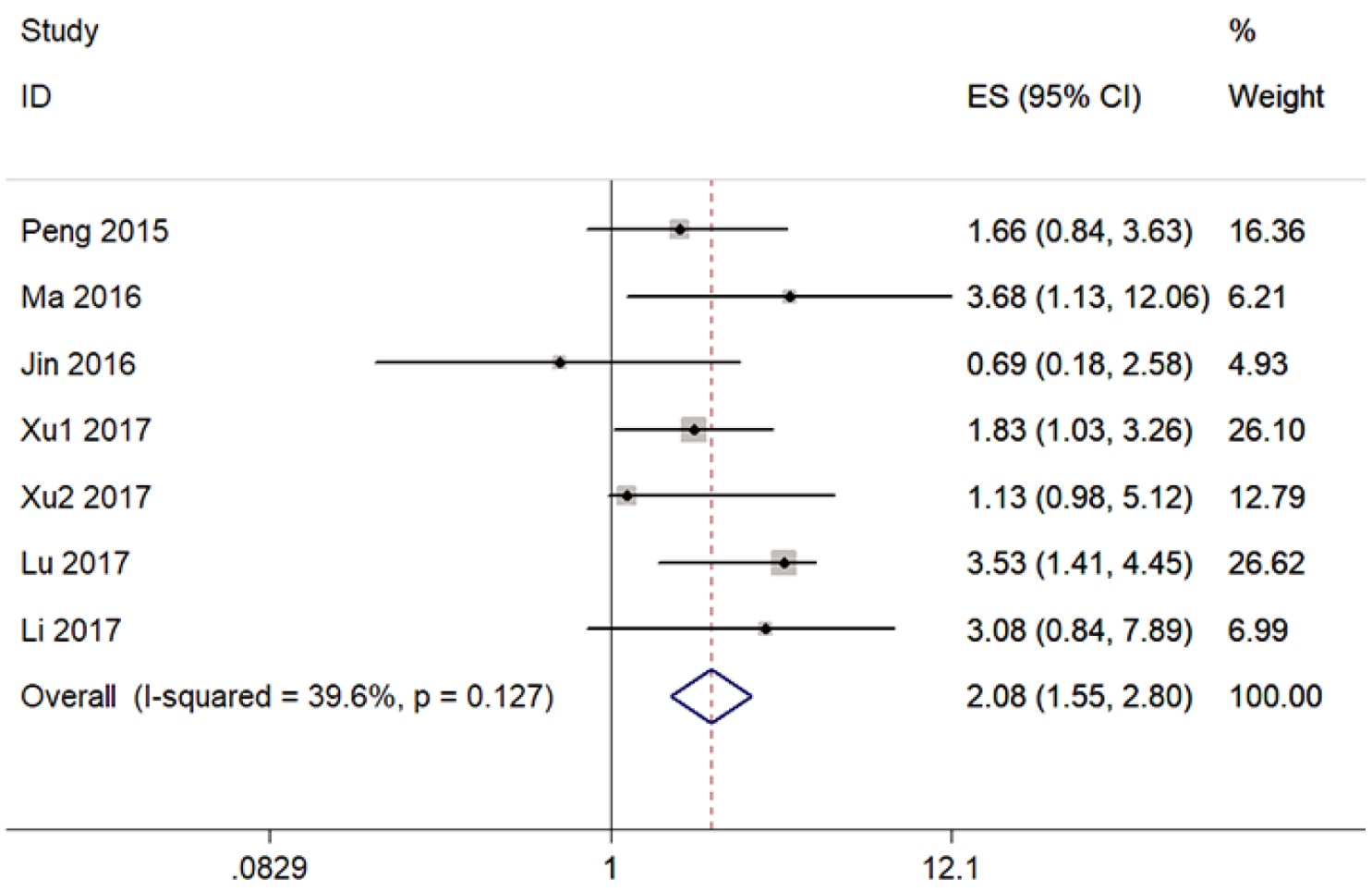

Figure 2: Forest plot for the association between PANDAR expression with overall survival (OS). 
According to the urgently needed of potential prognostic biomarkers for cancer patients, we firstly performed the present comprehensive and detailed metaanalysis to investigate the clinical prognostic role of PANDAR in diverse kinds of carcinomas. Ten studies including 1125 patients were pooled at first in this study, and the results indicate that the promoted expression of PANDAR was correlated with poor prognosis and the pooled HR was 1.64 (95\% CI: 0.89-2.89, $P=0.086)$. Since the significant heterogeneity $\left(I^{2}=80 \%\right)$ was observed across the studies, subgroup analysis and sensitivity analysis were performed to seek the source of heterogeneity. We discovered that only by excluding the study (Han et al. 2015) from the pooled analysis, the heterogeneity could be significantly reduced to lower than $50 \%$, which made the result more stable and convincing. In addition, we noticed that the expression of PANDAR is lower in NSCLC tissues compared with normal tissues and promoted PANDAR level can estimate better outcome in lung cancer, which was not consistent with most of other studies included in this meta-analysis [26]. Similarly, down regulation of IncRNA SPRY4-IT1 and TUG1 has been found to predict shorter OS in patients with NSCLC, which also contradicts with main conclusion in most other cancer studies [39-42]. The divergence was maybe ascribed to disease specific expression pattern of lncRNA instead of pute protein-coding genes, and it remains to be explored in future studies. Considering of above, we excluded the mentioned study to get a more precise inference, and the

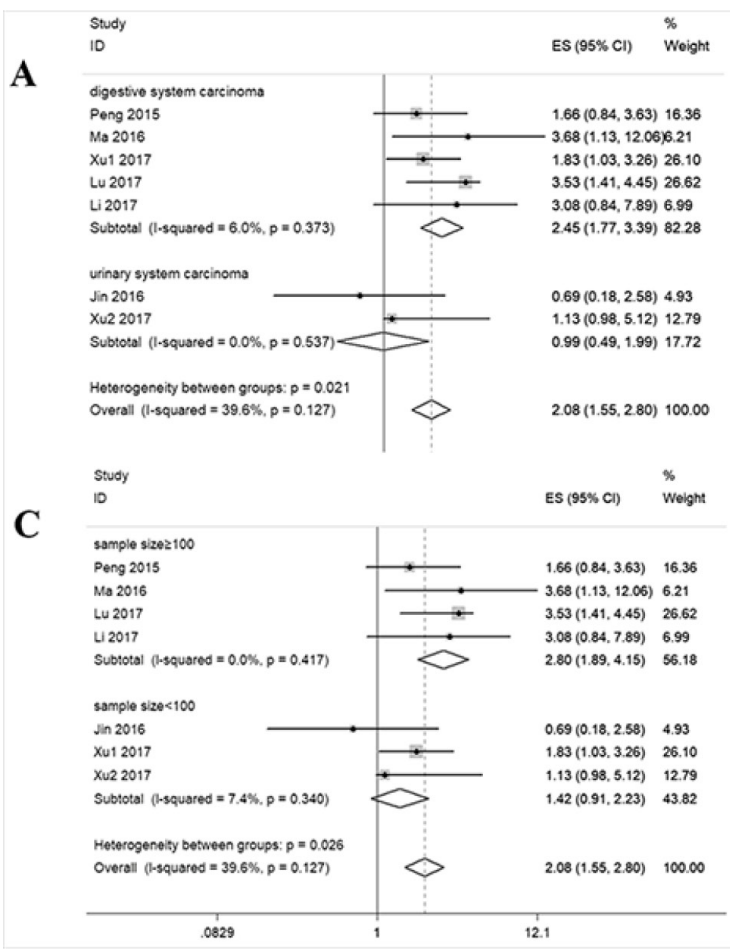

result indicates that enforced PANDAR expression was predictive of unfavorable OS in various carcinomas except for NSCLC $(\mathrm{HR}=2.08,95 \% \mathrm{CI}$ : $1.55-2.80, P=0.000)$. In the following subgroup analysis, a significant association between increased PANDAR and shorter OS was found in studies with high quality, sufficient sample size $(\geq 100)$ and ample follow-up time ( $\geq 60$ months). Notably, the promoted PANDAR level was correlated with poor prognosis in digestive system but not in non-digestive malignancies. Meanwhile, the pooled data of eligible studies also indicated that high PANDAR expression was significantly correlated with poor grade cancer (pooled OR $=2.80,95 \%$ CI $1.57-$ $4.99, p<0.001$ ), positive lymph node metastasis (pooled $\mathrm{OR}=2.92,95 \%$ CI $1.92-4.45, p<0.001)$, larger tumor size $(\mathrm{OR}=1.41,95 \% \mathrm{CI}=1.04-1.89, P=0.03)$, and poor tumor differentiation $(\mathrm{OR}=1.53,95 \% \mathrm{CI}=1.09-2.15, P=0.01)$.

Nonetheless, there were still several limitations in the meta-analysis. First, the total sample size was relatively small and the patients included were all from China, which might lead to unavoidable bias. Second, some of the HRs were estimated by reconstructing survival curves. In addition, the cut off definition was not elucidated in some studies, and reported ones were not consistent either, which could probably account for some discordance in included studies. Finally, publication bias might exist, despite the fact that no obvious publication bias was observed revealed in sensitivity analysis as well as funnel plot analysis.

In conclusion, although some limitations mentioned existed, it was preliminarily concluded that promoted

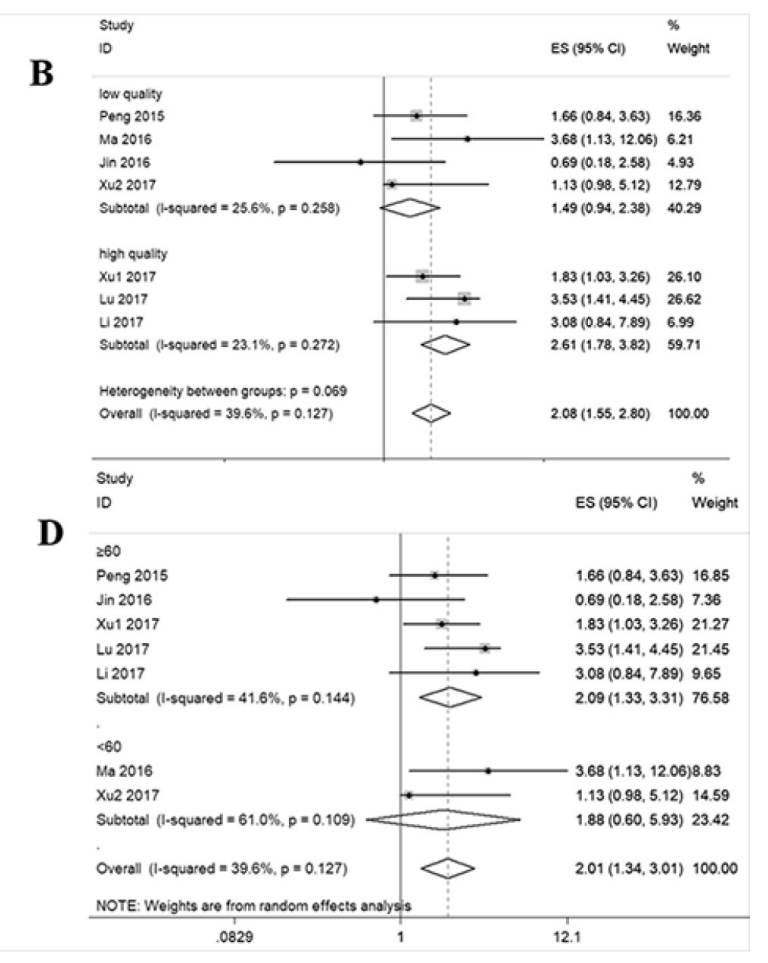

Figure 3: Stratified analyses for the association between PANDAR expression with overall survival (OS). (A) Subg $\neg$ roup analysis of HRs of OS by cancer type. (B) Subgroup analysis of HRs of OS by study quality. (C) Subgroup analysis of HRs of OS by sample size. (D) Subgroup analysis of HRs of OS by follow up months. 
PANDAR may be considered as a credible unfavorable prognostic factor in human cancers. In the future, more well designed and large-scale studies are required to verify and strengthen the findings of the present analysis.

\section{MATERIALS AND METHODS}

\section{Search strategy and literature selection}

Comprehensive literature search was conducted in PubMed, Google Scholar, Web of Science, Cochrane Library, CNKI (China National Knowledge Infrastructure), and Wanfang databases, and the cut-off date was defined as September 24, 2017. The searched terms in variably combinations were listed as follows: ("long noncoding RNA-" OR "Inc RNA-" OR "noncoding RNA-" OR "PANDAR") and ("cancer" OR "carcinoma" OR "tumor" OR "neoplasm") and ("prognosis" OR "prognostic" OR "survival" OR "metastasis"). We manually searched the references of primary literatures for potentially missing articles.

\section{Inclusion and exclusion criteria}

Inclusion criteria for the eligible studies included: 1) Definite diagnosis or histopathology confirmed for patients with cancer; 2) association of PANDAR expression levels with prognosis or clinicopathological features were

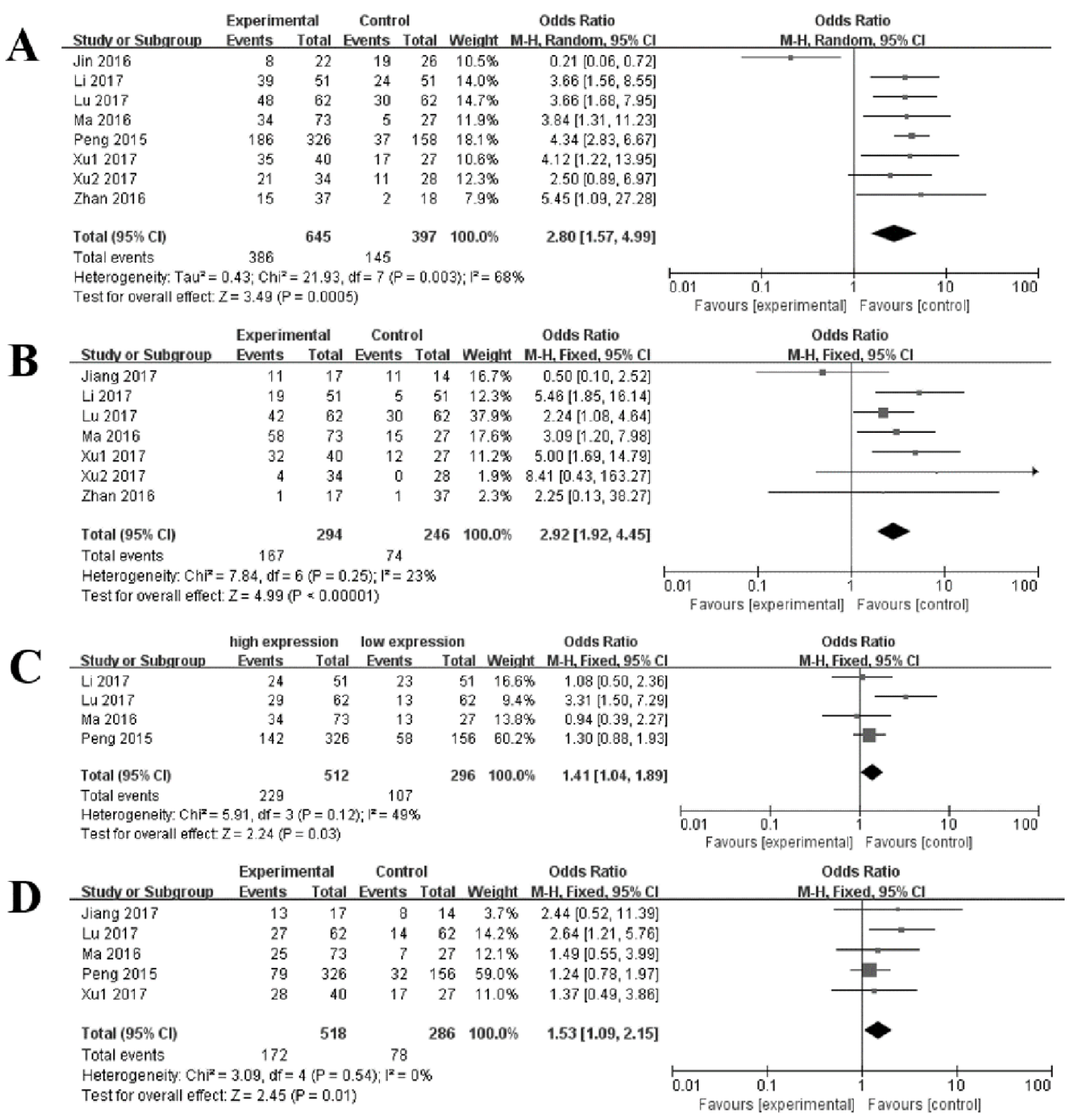

Figure 4: Forest plot for the association between PANDAR expression with TNM stage (A), lymph node metastasis (B), tumor size (C), tumor differentiation (D). 


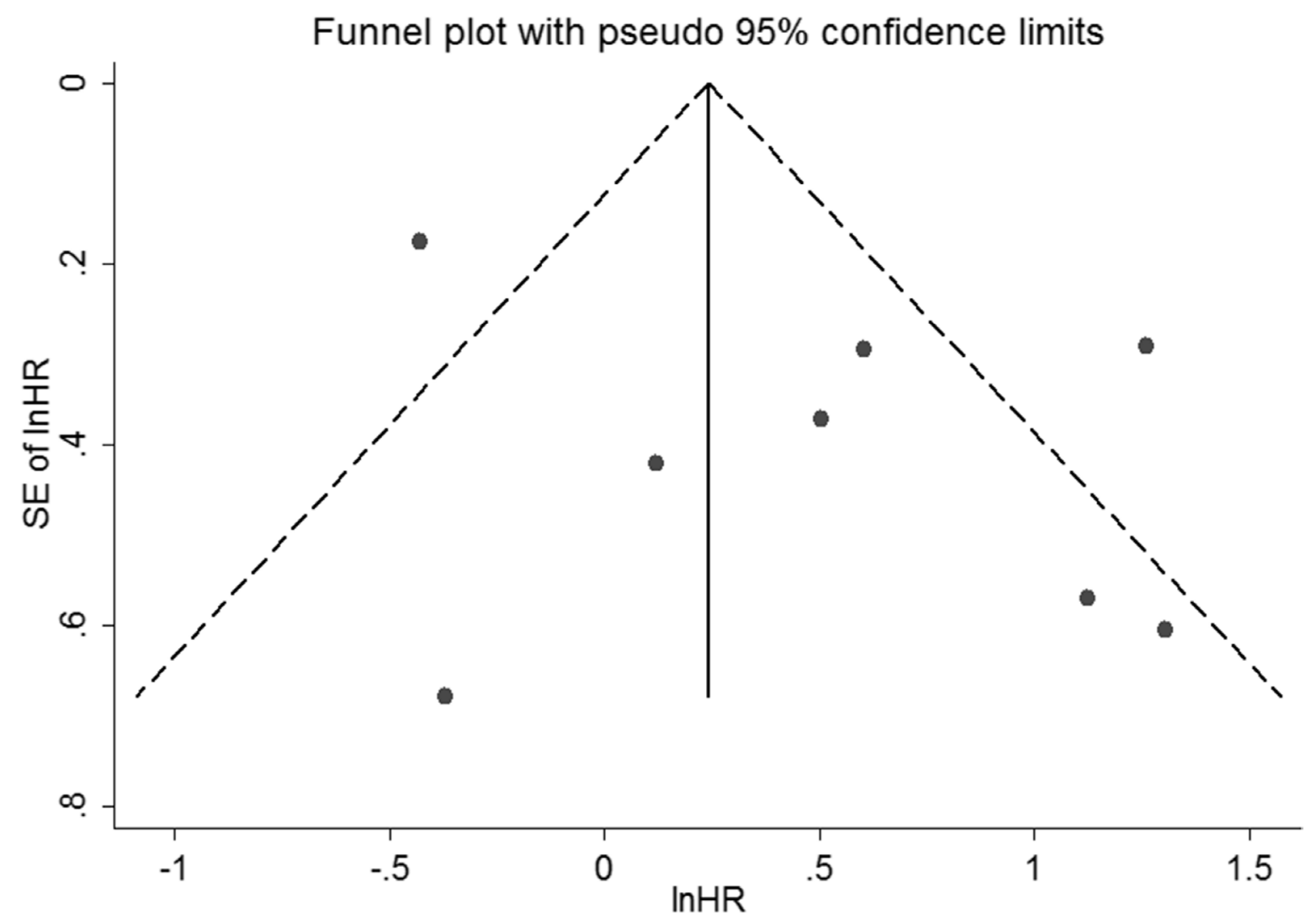

Figure 5: Funnel plot of the publication bias for OS.

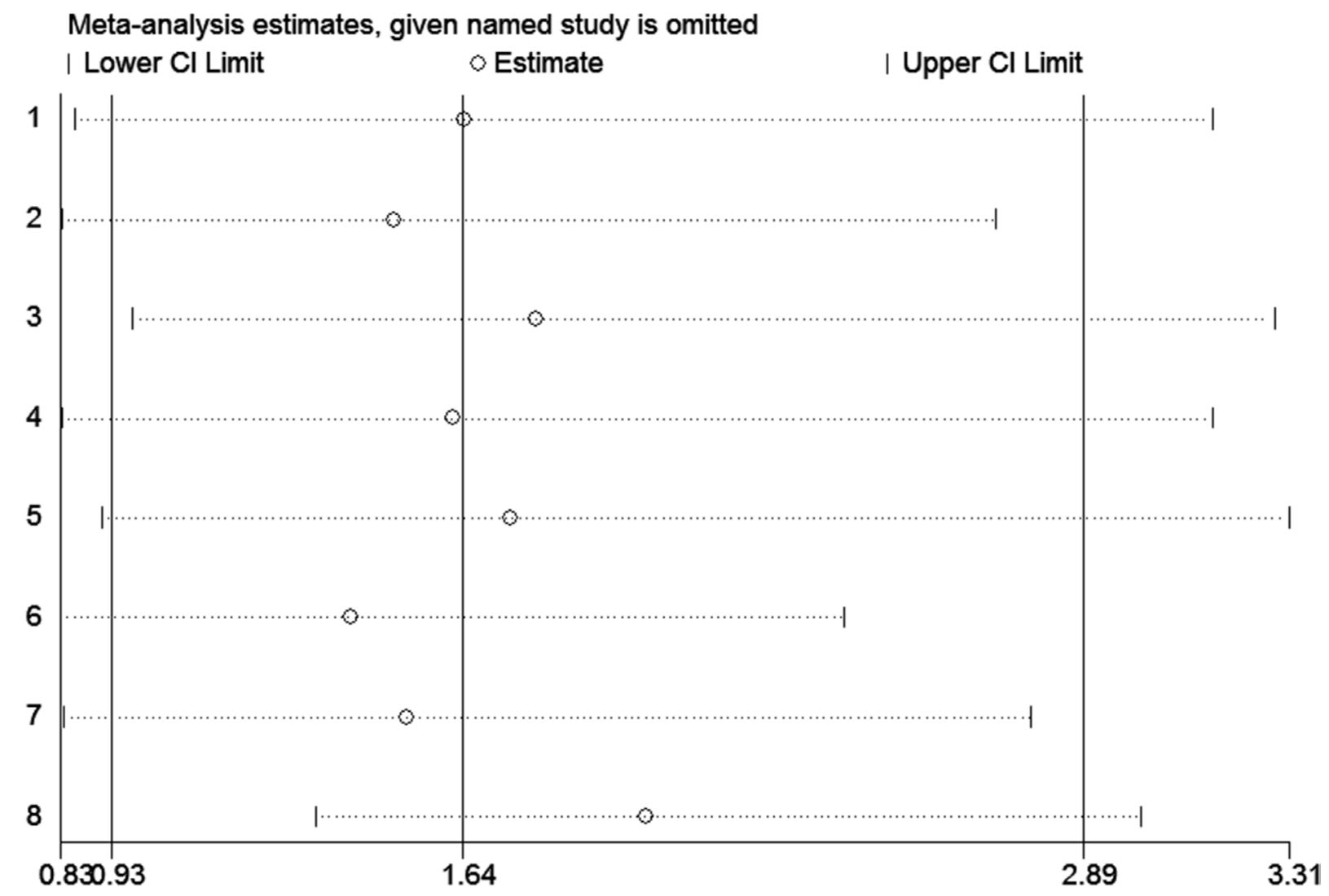

Figure 6: Sensitivity of PANDAR expression for OS. 
investigated; 3) patients were categorized into two groups according to high and low expression levels of PANDAR; 4) Sufficient original data for calculating hazard ratios (HR) and corresponding 95\% confidence intervals (CI).

Exclusion criteria for the articles included: 1) Studies without sufficient or usable data; 2) Studies without dichotomous IncRNA PANDAR expression; 3) Duplicated studies; 4) Basic research, animal experiments, case reports, editorials, expert opinions, letters, reviews and conference abstracts.

\section{Data extraction and quality assessment}

The data and information from the included studies were independently evaluated by two investigators (XY and YTZ). The following information were extracted from each eligible study: 1) first authors, publication year, country, sample size, tumor type, follow-up time; 2) criteria for defining high expression level of PANDAR and low expression level of PANDAR, method for detecting PANDAR expression; 3) $\mathrm{HR}$ and its corresponding 95\% CI of lncRNA PANDAR for overall survival, the clinicopathological parameters including TNM stage, lymph node metastasis, tumor size, local invasion and tumor differentiation. If only Kaplan-Meier curves were provided in studies, the survival rates were extracted from the graphical survival plots and the calculated HR and 95\% CI was determined following the published methods [43]. Multivariate analysis was preferred to extract because of higher precision when both univariate and multivariate analysis were provided. The quality of included studies was assessed based on Reporting Recommendations for Tumor Marker Prognostic Studies (REMARK) guideline (Supplementary Figure 1), the study scores ranged from $30 \%$ to $85 \%$, and studies with more than $75 \%$ scores could be regarded as high quality. The detailed assessment was show in Supplementary Table 1.

\section{Statistical analysis}

1) The meta-analysis was performed with Stata SE12.0 (Stata Corporation) and RevMan 5.3 software. 2) HRs and 95\% CIs were utilized to assess the association of PANDAR expression with patients prognosis. Odds Ratios (ORs) were performed to estimate the association of PANDAR expression with TNM stage, lymph node metastasis, tumor size, local invasion and tumor differentiation. An HR > 1 signifies that patients with high PANDAR expression have a poor prognosis. 3) The test for heterogeneity was carried out using Chi square-based $Q$ test and $\mathrm{I}^{2}$ statistics. A $p$ value of $<0.05$ or an $I^{2}$ value of $>50 \%$ was considered statistically significant. The fixed effects model was applied in the absence of significant heterogeneity, otherwise the random effects model was used. 4) The publication bias was estimated by the funnel plot and Begg's bias test $(P$ value $<0.05$ was considered statistically significant) [44]. The sensitivity analysis was also carried out to assess the stability of the results.

\section{Abbreviations}

LncRNA, long non-coding RNA; ncRNA, noncoding RNA; OS, overall survival; HR, hazard ratio; OR, odds ratios; CI, confidence interval; lincRNA, intergenic lncRNA; HC, hepatocellular carcinoma; $\mathrm{GC}$, gastric cancer; RCC, renal cell carcinoma; $\mathrm{CC}$, cholangio carcinoma; CCRCC, clear cell renal cell carcinoma; CRC, colorectal cancer; NSCLC, non-small cell lung cancer; BC, bladder cancer; PDAC, pancreatic ductal Adenocarcinoma; REMARK, reporting recommendations for tumor marker prognostic studies.

\section{Author contributions}

XY, MXL, WHS conceived and designed the study. $X Y$ and YTZ searched databases and extracted the data. JW, QTW and QQZ analyzed and checked the results of the data. FWL and LMC made some Tables and Figures. $\mathrm{XY}$ wrote the manuscript. All authors reviewed the final manuscript.

\section{CONFLICTS OF INTEREST}

All the authors declared that there are no conflicts of interest.

\section{FUNDING}

This study was supported by the National Natural Science Foundation of China (Grant No. 81330002).

\section{REFERENCES}

1. Siegel RL, Miller KD, Jemal A. Cancer Statistics, 2017. CA Cancer J Clin. 2017; 67:7-30. https://doi.org/10.3322/ caac. 21387.

2. Bray F, Jemal A, Grey N, Ferlay J, Forman D. Global cancer transitions according to the Human Development Index (2008-2030): a population-based study. Lancet Oncol. 2012; 13:790-801. https://doi.org/10.1016/s14702045(12)70211-5.

3. Shimizu Y, Yasui K, Matsueda K, Yanagisawa A, Yamao $\mathrm{K}$. Small carcinoma of the pancreas is curable: new computed tomography finding, pathological study and postoperative results from a single institute. J Gastroenterol Hepatol. 2005; 20:1591-4. https://doi.org/10.1111/j.14401746.2005.03895.x.

4. Borrebaeck CA. Precision diagnostics: moving towards protein biomarker signatures of clinical utility in cancer. Nat Rev Cancer. 2017; 17:199-204. https://doi.org/10.1038/ nrc.2016.153.

5. Esteller M. Non-coding RNAs in human disease. Nat Rev Genet. 2011; 12:861-74. https://doi.org/10.1038/nrg3074. 
6. Ponting CP, Oliver PL, Reik W. Evolution and functions of long noncoding RNAs. Cell. 2009; 136:629-41. https://doi. org/10.1016/j.cell.2009.02.006.

7. Liu Y, Zeng Y, Liu L, Zhuang C, Fu X, Huang W, Cai Z. Synthesizing AND gate genetic circuits based on CRISPR-Cas9 for identification of bladder cancer cells. Nat Commun. 2014; 5:5393. https://doi.org/10.1038/ ncomms6393.

8. Guttman M, Amit I, Garber M, French C, Lin MF, Feldser D, Huarte M, Zuk O, Carey BW, Cassady JP, Cabili MN, Jaenisch R, Mikkelsen TS, et al. Chromatin signature reveals over a thousand highly conserved large non-coding RNAs in mammals. Nature. 2009; 458:223-7. https://doi. org/10.1038/nature07672.

9. Huarte M, Guttman M, Feldser D, Garber M, Koziol MJ, Kenzelmann-Broz D, Khalil AM, Zuk O, Amit I, Rabani M, Attardi LD, Regev A, Lander ES, et al. A large intergenic noncoding RNA induced by p53 mediates global gene repression in the p53 response. Cell. 2010; 142:409-19. https://doi.org/10.1016/j.cell.2010.06.040.

10. Zheng GX, Do BT, Webster DE, Khavari PA, Chang HY. Dicer-microRNA-Myc circuit promotes transcription of hundreds of long noncoding RNAs. Nat Struct Mol Biol. 2014; 21:585-90. https://doi.org/10.1038/nsmb.2842.

11. Wang ZQ, He CY, Hu L, Shi HP, Li JF, Gu QL, Su LP, Liu BY, Li C, Zhu Z. Long noncoding RNA UCA1 promotes tumour metastasis by inducing GRK2 degradation in gastric cancer. Cancer Lett. 2017; 408:10-21.

12. Tran D, Kessler C, Niehus S, Mahnkopf M, Koch A, Tamura T. Myc target gene, long intergenic noncoding RNA, Linc00176 in hepatocellular carcinoma regulates cell cycle and cell survival by titrating tumor suppressor microRNAs. Oncogene. 2017.

13. Cesana M, Cacchiarelli D, Legnini I, Santini T, Sthandier O, Chinappi M, Tramontano A, Bozzoni I. A long noncoding RNA controls muscle differentiation by functioning as a competing endogenous RNA. Cell. 2011; 147:358-69. https://doi.org/10.1016/j.cell.2011.09.028.

14. Salmena L, Poliseno L, Tay Y, Kats L, Pandolfi PP. A ceRNA hypothesis: the Rosetta stone of a hidden RNA language? Cell. 2011; 146:353-8.

15. Jiang R, Tang J, Chen Y, Deng L, Ji J, Xie Y, Wang K, Jia W, Chu W, Sun B. The long noncoding RNA lnc-EGFR stimulates T-regulatory cells differentiation thus promoting hepatocellular carcinoma immune evasion. Nat Commun. 2017; 8:15129.

16. Li D, Liu X, Zhou J, Hu J, Zhang D, Liu J, Qiao Y, Zhan Q. Long noncoding RNA HULC modulates the phosphorylation of YB-1 through serving as a scaffold of extracellular signal-regulated kinase and YB-1 to enhance hepatocarcinogenesis. Hepatology. 2017; 65:1612-27.

17. Wu X, Wang F, Li H, Hu Y, Jiang L, Zhang F, Li M, Wang $\mathrm{X}$, Jin Y, Zhang Y, Lu W, Wu W, Shu Y, et al. LncRNAPAGBC acts as a microRNA sponge and promotes gallbladder tumorigenesis. EMBO Rep. 2017.
18. Tsai MC, Spitale RC, Chang HY. Long intergenic noncoding RNAs: new links in cancer progression. Cancer Res. 2011; 71: 3-7. https://doi.org/10.1158/0008-5472.can-10-2483.

19. Hung T, Wang Y, Lin MF, Koegel AK, Kotake Y, Grant GD, Horlings HM, Shah N, Umbricht C, Wang P, Kong B, Langerod A, Borresen-Dale AL, et al. Extensive and coordinated transcription of noncoding RNAs within cellcycle promoters. Nat Genet. 2011; 43:621-9. https://doi. org/10.1038/ng.848.

20. Sang Y, Tang J, Li S, Li L, Tang X, Cheng C, Luo Y, Qian $X$, Deng LM, Liu L, Lv XB. LncRNA PANDAR regulates the G1/S transition of breast cancer cells by suppressing p16(INK4A) expression. Sci Rep. 2016; 6:22366. https:// doi.org/10.1038/srep22366.

21. Zhan Y, Lin J, Liu Y, Chen M, Chen X, Zhuang C, Liu L, Xu W, Chen Z, He A, Zhang Q, Sun X, Zhao G, et al. Upregulation of long non-coding RNA PANDAR is associated with poor prognosis and promotes tumorigenesis in bladder cancer. J Exp Clin Cancer Res. 2016; 35:83. https://doi. org/10.1186/s13046-016-0354-7.

22. Li Z, Gao B, Hao S, Tian W, Chen Y, Wang L, Zhang X, Luo D. Knockdown of lncRNA-PANDAR suppresses the proliferation, cell cycle and promotes apoptosis in thyroid cancer cells. EXCLI J. 2017; 16:354-62. https://doi. org/10.17179/excli2017-113.

23. Kotake Y, Goto T, Naemura M, Inoue Y, Okamoto H, Tahara K. Long Noncoding RNA PANDA Positively Regulates Proliferation of Osteosarcoma Cells. Anticancer Res. 2017; 37:81-5. https://doi.org/10.21873/anticanres.11292.

24. Chen T, Yang P, Wang H, He ZY. Silence of long noncoding RNA PANDAR switches low-dose curcumin-induced senescence to apoptosis in colorectal cancer cells. Onco Targets Ther. 2017; 10:483-91. https://doi.org/10.2147/ott.s127547.

25. Ruan W, Wang P, Feng S, Xue Y, Li Y. Long non-coding RNA small nucleolar RNA host gene 12 (SNHG12) promotes cell proliferation and migration by upregulating angiomotin gene expression in human osteosarcoma cells. Tumour Biol. 2016; 37:4065-73. https://doi.org/10.1007/ s13277-015-4256-7.

26. Han L, Zhang EB, Yin DD, Kong R, Xu TP, Chen WM, Xia R, Shu YQ, De W. Low expression of long noncoding RNA PANDAR predicts a poor prognosis of non-small cell lung cancer and affects cell apoptosis by regulating Bcl2. Cell Death Dis. 2015; 6:e1665. https://doi.org/10.1038/ cddis.2015.30.

27. Jin L, Li Y, He T. Expression and clinical significance of long non-coding RNA PANDAR in renal cell carcinoma. Acta Universitatis Medicinalis Anhui. 2016.

28. Li X, Wang F, Sun Y, Fan Q, Cui G. Expression of long non-coding RNA PANDAR and its prognostic value in colorectal cancer patients. Int J Biol Markers. 2017; 32: e218-e23. https://doi.org/10.5301/jbm.5000249.

29. Lu M, Liu Z, Li B, Wang G, Li D, Zhu Y. The high expression of long non-coding RNA PANDAR indicates 
a poor prognosis for colorectal cancer and promotes metastasis by EMT pathway. Journal of Cancer Research and Clinical Oncology. 2017; 143:71-81. https://doi. org/10.1007/s00432-016-2252-y.

30. Ma P, Xu T, Huang M, Shu Y. Increased expression of LncRNA PANDAR predicts a poor prognosis in gastric cancer. Biomed Pharmacother. 2016; 78: 172-6. https://doi. org/10.1016/j.biopha.2016.01.025.

31. Peng W, Fan H. Long non-coding RNA PANDAR correlates with poor prognosis and promotes tumorigenesis in hepatocellular carcinoma. Biomed Pharmacother. 2015; 72:113-8. https://doi.org/10.1016/j.biopha.2015.04.014.

32. Xu Y, Jiang X, Cui Y. Upregulated long noncoding RNA PANDAR predicts an unfavorable prognosis and promotes tumorigenesis in cholangiocarcinoma. OncoTargets and Therapy. 2017; Volume 10:2873-83. https://doi. org/10.2147/ott.s137044.

33. Xu Y, Tong Y, Zhu J, Lei Z, Wan L, Zhu X, Ye F, Xie L. An increase in long non-coding RNA PANDAR is associated with poor prognosis in clear cell renal cell carcinoma. BMC Cancer. 2017; 17:373. https://doi.org/10.1186/s12885-0173339-9.

34. Jiang Y, Feng E, Sun L, Jin W, You Y, Yao Y, Xu Y. An increased expression of long non-coding RNA PANDAR promotes cell proliferation and inhibits cell apoptosis in pancreatic ductal adenocarcinoma. Biomed Pharmacother. 2017; 95:685-91.

35. Lalevee S, Feil R. Long noncoding RNAs in human disease: emerging mechanisms and therapeutic strategies. Epigenomics. 2015; 7:877-9. https://doi.org/10.2217/ epi.15.55.

36. Wapinski O, Chang HY. Long noncoding RNAs and human disease. Trends Cell Biol. 2011; 21:354-61. https://doi. org/10.1016/j.tcb.2011.04.001.

37. Wang F, Ni H, Sun F, Li M, Chen L. Overexpression of lncRNA AFAP1-AS1 correlates with poor prognosis and promotes tumorigenesis in colorectal cancer. Biomed
Pharmacother. 2016; 81:152-9. https://doi.org/10.1016/j. biopha.2016.04.009.

38. Gao H, Song X, Kang T, Yan B, Feng L, Gao L, Ai L, Liu $\mathrm{X}, \mathrm{Yu}$ J, Li H. Long noncoding RNA CRNDE functions as a competing endogenous RNA to promote metastasis and oxaliplatin resistance by sponging miR-136 in colorectal cancer. Onco Targets Ther. 2017; 10:205-16. https:/doi. org/10.2147/ott.s116178.

39. Liu J, Lin J, Li Y, Zhang Y, Chen X. Prognostic role of lncRNA TUG1 for cancer outcome: Evidence from 840 cancer patients. Oncotarget. 2017; 8:50051-50060. https://doi.org/10.18632/oncotarget.17844.

40. Sun M, Liu XH, Lu KH, Nie FQ, Xia R, Kong R, Yang JS, Xu TP, Liu YW, Zou YF, Lu BB, Yin R, Zhang EB, et al. EZH2-mediated epigenetic suppression of long noncoding RNA SPRY4-IT1 promotes NSCLC cell proliferation and metastasis by affecting the epithelial-mesenchymal transition. Cell Death Dis. 2014; 5:e1298. https://doi. org/10.1038/cddis.2014.256.

41. Wang M, Dong X, Feng Y, Sun H, Shan N, Lu T. Prognostic role of the long non-coding RNA, SPRY4 Intronic Transcript 1, in patients with cancer: a meta-analysis. Oncotarget. 2017; 8:33713-24. https://doi.org/10.18632/ oncotarget.16735.

42. Zhang EB, Yin DD, Sun M, Kong R, Liu XH, You LH, Han L, Xia R, Wang KM, Yang JS, De W, Shu YQ, Wang ZX. P53-regulated long non-coding RNA TUG1 affects cell proliferation in human non-small cell lung cancer, partly through epigenetically regulating HOXB7 expression. Cell Death Dis. 2014; 5:e1243. https://doi.org/10.1038/ cddis.2014.201.

43. Tierney JF, Stewart LA, Ghersi D, Burdett S, Sydes MR. Practical methods for incorporating summary time-to-event data into meta-analysis. Trials. 2007; 8:16.

44. Egger M, Davey Smith G, Schneider M, Minder C. Bias in meta-analysis detected by a simple, graphical test. BMJ. 1997; 315:629-34. 